\title{
The Analysis of Motor Skill and Body Mass Index Development of Early Children in Rural Areas
}

\author{
Wulandari Putri*, Mesa Rahmi Stephani, Gano Sumarno \\ Faculty of Sport and Health Education \\ Universitas Pendidikan Indonesia \\ Bandung, Indonesia \\ *wulandariputri@upi.edu
}

\begin{abstract}
Motor development on early childhood is a fundamental milestone for the children, while Body Mass Index (BMI) is an essential predictor for various aspects of their health such as nutrition sufficiency. This study was aimed at examining the children motor development and body mass index in rural area. The study was a descriptive study involving 55 children aged 4-5 taken from preschools and kindergartens in rural area. To measure the children motor development, Ages and Stages Questionnaire (ASQ) 3rd Edition was used. Meanwhile, to calculate the children Body Mass Index (BMI), the children height and weight were measured by using weight scale and portable stadiometer. The data analysis process was conducted by using descriptive statistics data analysis. The findings showed that motor development, including gross motor development and fine motor development, of the majority of the children involved in the study were above the cut off category. Only small number of the children who needed monitoring or further professional assessment. The finding also presented that the weight category of the children in the rural area were mostly in thin category, only small number of the children who were in the normal category. There was no overweight nor obese case found in the study. The result of the study implies that most of the children in the rural area have acquired a good motor development. However, the nutrition sufficiency has to be taken into account for most of them were in the thin category that might indicate the nutrition insufficiency in their living area.
\end{abstract}

Keywords: body mass index, early childhood development, fine motor skill, gross motor, motor skill development

\section{INTRODUCTION}

The development of early childhood motor skills is fundamental for children other aspects of development including their communication and social domain [1], psychological domain [2], and physical activity enjoyment in the future $[3,4]$. In the social and communication domain, motor development provides opportunities to infants to obtain knowledge of the world [1]. Previous research had highlighted an essential relationship between motor skills and the development of language, social cognition, and social interactions [1]. According to Wang et al., motor development and communicative development are associated [5]. The study of Wang et al. shows that early motor skills could predict later communication skills [5]. In the psychological aspect, the study of [2] found that a young child's gross motor development, from 4 months to 4 years, predicts the level of anxious/depressive symptoms at school age. It is found that gross motor stability had an impact on both the children's anxiety problems and also their anxious/depressed scores at school age [2].

The attainment of adequate motor skills is a vital developmental task in childhood [3], including for their future physical activity. Early motor skill development could have influences on physical activity enjoyment as well as long-term physical activity and motor skill performance [4]. According to [3], adequate motor skills are fundamental for children participating in age-related physical activities. Gross motor skills is believed to have a central role for maintaining sufficient level of physical activity (PA) during life course [3]. There is emerging and consistent evidence presenting that adequate motor skill competence, particularly locomotor and gross motor skills, is associated with improved physical activity levels during the preschool, child, and adolescent years [4]. In the other hand, research also proves that physical activity could also help increase fundamental-related movement skills [4]. Therefore, both physical activity and motor development have a reciprocal relationship.

A child's development is established upon several related domains that are influenced by social, environmental, and biological factors which are vulnerable to adverse or favorable situations [6]. Regarding environmental factor, each context of place has specific demands on the physical activities and motor competencies of infants and children [7]. Therefore, the environment in which a child is reared is important since the motor development occurs in a specific social context [7]. In the biological context, body mass index might have an association with the motor development. The findings of the study of Morano et al. indicate that childhood obesity might have adverse effects on gross motor development [8]. In comparison with non-overweight peers, overweight participants exposed poorer performance on object-control tasks and locomotor task [8]. In addition, high subcutaneous fat and pediatric overweight are associated with delayed infant motor development [9]. It may conclude that obesity in children might had impact on their motor development.

To support and to improve the children motor development, various intervention could be taken to prevent adverse consequences on other domains in the future. Since motor 
development could be affected by the environment [7], providing essential resources that promote cognitive and motor skills in young children at home is important [6]. Moreover, the study of Draper et al. suggests a program named Little Champs program that was proven that even limited exposure to a low intensity program for motor development can positively impact cognitive function and gross motor skills in disadvantaged preschoolers [10]

Regarding earlier explanations, motor development has crucial impacts on other aspects of development on children. The motor development itself could be affected by the social cultural context in which a child is raised that forms certain demands for their motor behavior and esteems specific aspects of motor development and impairing others [7]. Children in the rural area has a different social cultural and environmental contexts. Thus, their motor development might be also different. Therefore, this research was conducted with the aim to examine the children motor development in the rural area. This research also tried to examine their Body Mass Index to describe their weight status that may have impacts on their motor development. The result of the study is expected to provide beneficial information for the researcher, practitioner, and other stakeholders who are working with children and their development, especially their motor development.

\section{MethodS}

The method of the study for examining the students' basic motor development and Body Mass Index (BMI) was descriptive study method with ex-post facto study design. The population of the study involved Preschools and Kindergartens in rural areas. The participants of the study were the children chosen purposively according to their age and their living area category. The children should be $4-5$ year old and lived in rural area. The parents of the participants were firstly signing consent form stating they allowed the children to involve in the study. The motor development was used by using Ages and Stages Questionnaire (ASQ) 3rd Edition [11]. Meanwhile, the Body Mass Index of the children was calculated by firstly measuring their height and weight. The measuring devices used to measure their height was portable stadiometer, while their weight was measured by digital weight scale. The analysis of the obtained data was by employing statistics descriptive data analysis.

\section{RESULT AND DISCUSSION}

The study was aimed at examining the early childhood motor development in the rural area, as well as their body mass index status. The result of the analysis of the obtained data are presented in the following section. The findings include two main parts including children motor skill development and children body mass index.

\section{A. Children Motor Skill Development}

Figure 1 below presents the result of the analysis of the gross motor skill development of the children in the rural area.

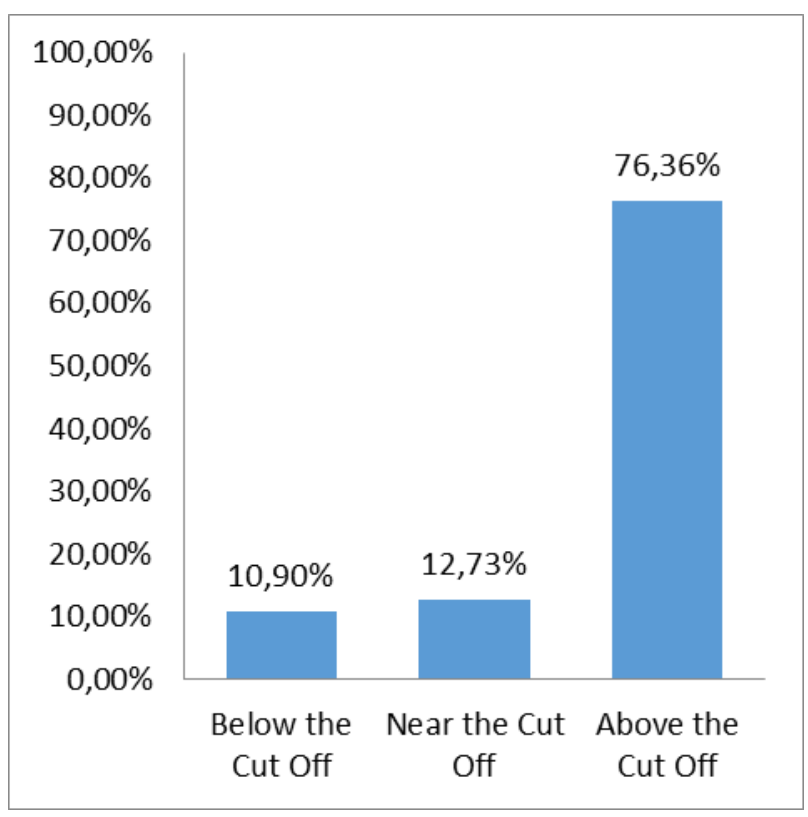

Fig. 1. Children gross motor development.

Figure 1. above shows that most of the children $(76.36 \%)$ were in the above the cut off category, small number of the children $(12.73 \%)$ were in the near the cut off category, and only a small number of the children $(10.90 \%)$ who were in the below the cut off category. Above the cut off category means that the children had mastered the sufficient motor skill development required in their stage of development. Near the cut off category means that the children needed more learning activities and monitoring. Meanwhile, below the cut off category indicates that the children further assessment with professional.

Figure 2 contains the result of analysis of obtained data related to children fine motor skill development in the rural area. The table can be seen as follows.

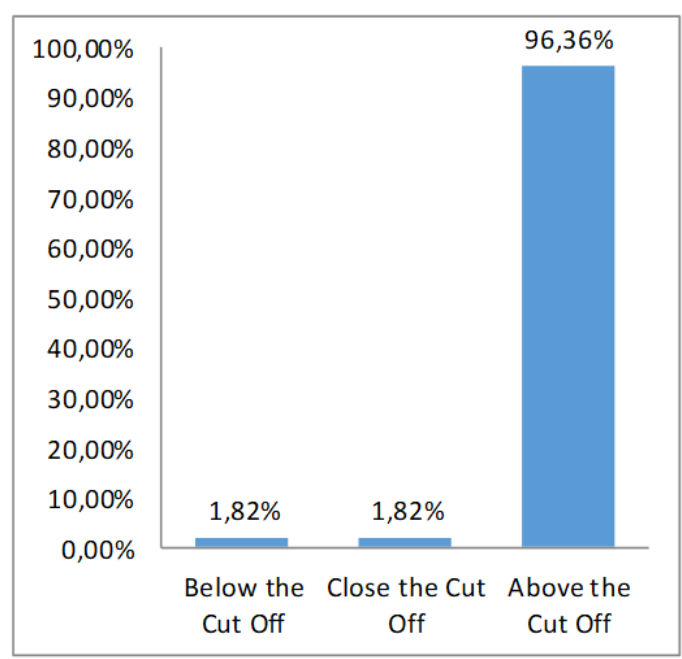

Fig. 2. Children fine motor skill development.

The Figure 2. above present that almost all of the children $(96.36 \%)$ were in the above the cut off category, only a very 
small number of the children who were in the close the cut off category $(1.82 \%)$ and in the below the cut off category $(1.82 \%)$. Similar to the gross motor skill development, the above the cut off category indicates that the children development is right in the schedule. Close the cut off category implies that the children need more activities and monitoring, while below the cut off category means that the children might need further professional assessment.

The result of the data analysis of the children gross and fine motor skill development shows that most of the children had acquired the task of motor development of their age period. Only a small number of the children who needed more activities, monitoring, and further professional assessment. The result might indicates that most of the children in the rural area have a good motor development. It is probably affected by their environment and their living area that belongs to rural category. As stated by Venetsanou and Kambas, the environment in which a child is nurtured is vital for their motor development as it arises in a specific social context [7]. Therefore, the good mastery of the motor development of the participants might be as a contribution from their environment. As the children lived in the rural area, they might had more spaces for doing physical activities and had more opportunities to spend their time for physical activities. However, it requires further investigation to assure the exact factors contributing to their motor skill mastery.

The finding concludes that the motor development of the most of the children in the rural area are right on their developmental schedule. However, we may not neglect that there is still a small number of the children who are left behind. They need more activities, monitoring, or even further professional assessment. For that problems, some intervention could be taken to improve their motor skill mastery. Providing an essential home affordances that give them more opportunities to improve and to stimulate their motor skill development might be effective. As stated by [6], there is a significant positive correlations between the dimensions of the home (daily activities and play materials) and global motor performance and fine-motor performance. One of the main categories of affordances includes play material - toys and play items that have a high likelihood of promoting optimal motor and physical development [6].

\section{B. Children Body Mass Index}

The children body mass index was calculated to categorize their weight status that might indicate their health condition. The children weight status is presented in Figure 3. below.

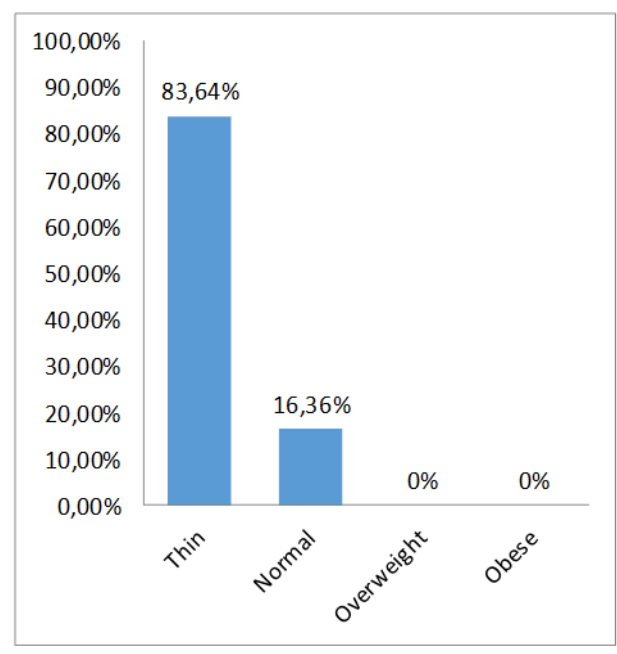

Fig. 3. Children weight status.

The Figure 3. above shows that most of the children $(83.64 \%)$ were in the thin category. Only small number of the children $(16.36 \%)$ were in normal category. In addition, there was no child found to be in the overweight nor obese category. This result indicates an interesting finding. The findings indicate that most of the children were in the thin category. Thin category might indicates that the children have a nutrition problem. Another interesting finding is that all of the children who were in the below the cut off category, indicating that they require further professional assessment, were in the thin category for their weight status. However, the further investigation is needed to find out the factors influence their nutrition status as well as the correlation between their motor development and their weight status. Therefore, it is too early to generalize the result of the finding.

\section{CONCLUSION}

The results of the study show that most of the children in the rural area have acquired an adequate motor skill development for their developmental age. Only a small number of them who need monitoring or professional assessment. The finding implies that their motor skill development might be affected by the environment in their living area. Since they lived in the rural area, they might have more spaces and opportunities to do activities that stimulate and develop their motor skill development. However, further study is needed to see the exact factor influencing their motor development. Moreover, regarding their body mass index, most of the children are in the thin category. Only small number of them who are in the normal category, while the case of overweight and obesity were not found. All of the children who need professional assessment for their motor development were found to be in the thin category. However, the further investigation is needed to find out the correlation between the weight status and motor development as well as the factor influencing children weight status in the rural area. The result of this study cannot be generalized due the limitation of participants, time spent, and the instrument used to collect that data. 
[5] M.V Wang, R. Lekhal, L.E. Aarø, S. Schjølberg, and M.V. Wang, "Child: Co-occurring development of early childhood communication and motor skills : results from a population-based longitudinal study," no. Iverson 2010, pp. 1-8, 2012.

This research was supported/partially supported by Lembaga Penelitian dan Pengabdian Masyarakat (LPPM) Universitas Pendidikan Indonesia. We would like to deliver our gratitude to all of participants and everyone involved in the study.

\section{REFERENCES}

[1] H.C. Leonard, E.L. Hill, H.C. Leonard, and E.L. Hill, "Review: The impact of motor development on typical and atypical social cognition and language : a systematic review," no. 3, pp. 163-170, 2014.

[2] J.P. Piek, N.C. Barrett, L.M. Smith, D. Rigoli, and N. Gasson, "Human Movement Science Do motor skills in infancy and early childhood predict anxious and depressive symptomatology at school age?," Hum. Mov. Sci., vol. 29, no. 5, pp. 777-786, 2010.

[3] A. Laukkanen, A. Pesola, M. Havu, A. Sääkslahti, and T. Finni, "Relationship between habitual physical activity and gross motor skills is multifaceted in 5- to 8-year-old children," pp. 1-9, 2013.

[4] P.D. Loprinzi, R.E. Davis, and Y.Fu, "NU," PMEDR, 2015.
[6] A.F. Miquelote, D.C.C. Santos, P.M. Cac, M.I.D.L. Montebelo, and C. Gabbard, "Infant Behavior and Development Effect of the home environment on motor and cognitive behavior of infants," vol. 35, pp. 329-334, 2012.

[7] F. Venetsanou and A. Kambas, "Environmental Factors Affecting Preschoolers ' Motor Development," pp. 319-327, 2010.

[8] M. Morano, D. Colella, and M. Caroli, "Gross motor skill performance in a sample of overweight and non-overweight preschool children," vol. 6, pp. 42-46, 2011.

[9] M. Slining, L.S. Adair, B.D. Goldman, J.B. Borja, and M. Bentley, "Infant overweight is associated with delayed motor development," The Journal of pediatrics, vol. 157(1), pp. 20-25, 2010.

[10] C.E. Draper, M. Achmat, J. Forbes, and E.V Lambert, "Early Child Development and Care Impact of a community-based programme for motor development on gross motor skills and cognitive function in preschool children from disadvantaged settings," 2013.

[11] J. Squires and D. Bricker, Ages \& Stages Questionnaires®, Third Edition (ASQ-3TM). Baltimore, MD: Paul H. Brookes Publishing Co., 2009. 